\title{
A COMUNICAÇÃO EM REDES DE EDUCAÇÃO AMBIENTAL
}

\author{
Gabriela Stefani ${ }^{1}$ \\ Silvia Cristina Vieira ${ }^{2}$ \\ Cristiane Hengler Corrêa Bernardo ${ }^{3}$
}

\section{RESUMO}

Refletir sobre o papel das redes sociais como espaço dialógico para a promoção da educação ambiental é o objetivo geral deste artigo. Diante do que se pretende, destaca-se como objetivo específico analisar as possibilidades trazidas pelo espaço virtual como cenário para o desenvolvimento da educação ambiental. Para tanto, utiliza-se a pesquisa bibliográfica, em levantamento nas principais bases de dados científicas, para consulta de fontes secundárias e na legislação pertinente à educação ambiental. Os dados coletados para efetuar a discussão acerca da temática abordada envolveram conceitos de redes; redes ambientais; educação e comunicação ambiental. Os resultados apontam para as potencialidades das redes para a promoção da educação ambiental, diante do grande poder de mobilização, do amplo alcance e da rapidez de propagação das informações. Ressalta-se que tais potencialidades estão associadas à qualidade dos vínculos de confiança estabelecidos entre os integrantes das redes, assim como da necessidade de ultrapassar as barreiras de comunicação presentes nesse ambiente virtual.

PALAVRAS-CHAVE: Comunicação Ambiental. Educação Ambiental. Redes Ambientais.

\section{COMMUNICATION IN ENVIRONMENTAL EDUCATION}

\section{NETWORKS}

\begin{abstract}
Reflect on the role of social networks as dialogic space for the promotion of the environmental education is the general purpose of this article. In the face of what is intended, it stands out as a specific objective to analyze the possibilities brought by the virtual space as the scenario for the development of the environmental education. For this, it uses the bibliographical research, in a survey in the main bases of scientific data, for consultation of secondary sources and in the relevant legislation on environmental education. The collected Data to develop the discussion about the theme addressed involved network concepts; environmental networks; environmental education and communication. The results point to the potentialities of networks for the promotion of the environmental education, before the great power of mobilization, the broad reach and the speed of propagation of information. It is noteworthy that such potentialities are associated with the quality of the trust bonds established between the network members, as well as the need to overcome the communication barriers contained in this virtual environment.
\end{abstract}

KEYWORDS: Environmental Communication. Environmental Education. Environmental networks.

\footnotetext{
${ }_{1}^{1}$ Graduanda em Administração. Unesp. E-mail: gastefani@ig.com.br

${ }^{2}$ Mestranda em Agronegócio e Desenvolvimento; Especialista em Gestão do Agronegócio e Graduada em Medicina Veterinária. Unesp. E-mail: tinavieiragomes@hotmail.com.br

${ }^{3}$ Doutora em Educação; mestre em comunicação midiática e graduada em jornalismo, Professora Assistente Doutora - Unesp. E-mail: cristiane@tupa.unesp.br
} 


\section{LA COMUNICACIÓN EN LAS REDES DE EDUCACIÓN}

\section{AMBIENTAL}

\section{RESUMEN}

Reflexionar sobre el papel de las redes sociales como espacio dialógico para la promoción de la educación ambiental es el propósito general de este artículo. A la vista de lo que se pretende, se destaca como un objetivo específico para analizar las posibilidades presentadas por el espacio virtual como escenario para el desarrollo de la educación ambiental. Para ello, utiliza la literatura en una encuesta realizada en las principales bases de datos científicos para la consulta de fuentes secundarias y la legislación pertinente en materia de educación ambiental. Los datos recogidos para llevar a cabo la discusión sobre el tema abordado conceptos involucrados redes; redes ambientales; educación y comunicación ambiental. Los resultados apuntan a la potencial de las redes para la promoción de la educación ambiental, antes de que el gran poder de movilización, el amplio alcance y la velocidad de propagación de la información. Es de destacar que estas capacidades están asociadas con la calidad de los vínculos de confianza que se establecen entre los miembros de las redes, así como la necesidad de superar las barreras de comunicación presentes en este entorno virtual.

PALABRAS CLAVE: Comunicación Ambiental. Educación Ambiental. Redes ambientales.

\section{INTRODUÇÃO}

As frequentes notícias de que a sociedade atual e sua constante evolução vêm degradando, de forma dramática e irresponsável, os recursos naturais do planeta, tornam as questões ambientais o centro das atenções e dos debates. Para compreender como se dá esse discurso em defesa do meio ambiente torna-se necessário analisar os fatos comunicacionais nas suas interfaces. A comunicação ambiental contribui para aumentar a circulação de informações nessa área, estimulando, desse modo, a realização de estudos, pesquisas e reflexões ambientais. (BARBOSA, 2011).

As empresas têm sido apontadas como as grandes vilãs da assolação ao meio ambiente, contribuindo em escala com o cenário atual do planeta, entretanto, os problemas ambientais não são apenas de responsabilidade das organizações empresariais. A questão ambiental é bastante complexa, pois há muitas vertentes que se cruzam e demandam análises específicas (OLIVEIRA e NADER, 2007).

As redes sociais têm hoje um grande poder de alcance e de mobilização, nesse sentido é que se vislumbra um importante espaço para o desenvolvimento de ações relacionadas à educação ambiental. Esse movimento já tem sido sentido e aproveitado por muitas Organizações Não Governamentais (ONGs) e até mesmo 
por empresas que têm alguma preocupação em atrelar sua imagem a de uma instituição social e ambientalmente responsável.

A visibilidade trazida hoje pela web às redes sociais é indiscutível, entretanto, a internet é somente uma das particularidades da imensa rede "invisível" que assinala as articulações sociopolíticas no Brasil (AGUIAR, 2007). Organizações ligadas às questões ambientais e sociais podem ser consideradas pioneiras na ordenação das redes sociais no país. Tal "start", no Brasil, teve início com a Conferência da Organização das Nações Unidas (ONU) sobre Meio Ambiente e Desenvolvimento (ECO 92), ocorrida no Rio de Janeiro. A partir de então as ONGs, assim como os movimentos sociais multiplicaram-se em redes espalhadas pelo país.

As redes ambientais surgiram para contribuir para com a sensibilização e com a conscientização da população para as questões ambientais; questões essas que vêm levando o ambiente em que se vive à sérias complicações, como o efeito estufa e o aquecimento global (ABRANTES, 2013).

Segundo o Ministério do Meio Ambiente (2008), as redes ambientais são espaços que promovem a interação, discussão, troca de conhecimentos sobre temáticas ambientais e também de mobilização política. Atuam como fomentadoras de informações às pessoas (profissionais e/ou instituições) ligadas à Educação Ambiental. São ambientes onde os usuários podem ler e comentar as notícias postadas, como também publicar suas ideias.

Nesse contexto, este artigo pretende refletir sobre o papel das redes sociais como espaço dialógico para a promoção da educação ambiental. Para tanto, por meio de um levantamento bibliográfico conceitual sobre redes; redes ambientais; educação ambiental e comunicação, buscou-se estabelecer uma análise sobre as possibilidades trazidas pelo espaço virtual como cenário, no qual se apresentam instrumentos de alto potencial comunicacional, que possam fomentar a consciência ambiental, ou, pelo menos, promover uma ampla discussão sobre a sua necessidade.

\section{OBJETIVOS}

Refletir sobre o papel das redes sociais como espaço dialógico para a promoção da educação ambiental é o objetivo geral deste artigo. 
Diante do que se pretende, destaca-se como objetivo específico analisar as possibilidades trazidas pelo espaço virtual como cenário para o desenvolvimento da educação ambiental.

\section{METODOLOGIA}

Para desenvolvimento deste artigo utilizou-se a pesquisa bibliográfica como procedimento de investigação. Diante da metodologia escolhida, a coleta de dados foi realizada por meio de base de dados científicos e em documentos jurídicos que conceituam educação ambiental e suas aplicações.

Os dados coletados tiveram como base a documentação indireta, tanto de fontes primárias (legislação) quanto de fontes secundárias (livros e artigo científicos).

As fases da pesquisa que geraram o presente artigo encaminharam-se da seguinte forma: primeiro delimitou-se a temática em redes de educação ambiental, ao mesmo tempo já se estabeleceu o objeto de análise. Após esse recorte procurouse reunir os conceitos necessários para traçar os elementos que caracterizam o locus de análise. Com o conceitual reunido e o contexto construído, foi possível estabelecer as relações entre estes, de modo a refletir e, a posteriori analisar, as potencialidades das redes para a educação ambiental com fins de atender o objetivo proposto.

\section{RESULTADOS E DISCUSSÕES}

Para que se possa atingir a proposta deste artigo, torna-se necessário que sejam colocados em discussão, primeiramente, os conceitos que deram base a essa análise e que amparam a construção dessa reflexão.

\subsection{REDES}

De modo a destrinchar o funcionamento de uma rede social, para compreendê-la diante da discussão em que esta se apresenta como locus, no qual 
se travam as relações dialógicas de comunicação que levam às possibilidades de desenvolvimento dos instrumentos da educação ambiental, torna-se imprescindível um breve resgate histórico que aborde a sua concepção.

As redes, como hoje são concebidas, começaram a ser analisadas a partir do ano de 1940, sobretudo, pelas áreas da sociologia, antropologia e da psicologia social (BARNES, 1972; ROGERS e KINCAID, 1981; SCOTT, 1992). Pesquisadores dos Estados Unidos, Inglaterra e Alemanha usaram metáforas como a árvore, a teia, a malha e a trama para criar um padrão descritivo dos fluxos informacionais e de suas conexões, desde os chamados nós ${ }^{4}$ até a complexidade dos rizomas ${ }^{5}$ (DELEUZE e GUATTARI, 1996).

Cerca de 50 anos mais tarde é que as redes sociais passam a merecer atenção das pesquisas no Brasil. Por volta dos anos de 1990 é que a academia brasileira se debruça sobre as novas formas de associação e de organização socioeconômicas, oriundas do período pós-ditadura, da globalização da economia e de uma proposta de desenvolvimento sustentável (AGUIAR, 2007).

As redes sociais podem ser definidas, de acordo com Aguiar (2007), como relações entre os indivíduos que se aproximam e interagem em benefício próprio ou em nome de um interesse comum, público ou de uma organização. Nesse sentido, as redes sociais podem ainda ser classificadas em informais e intencionais. As redes informais são as relações cotidianas, normalmente formadas por familiares, amigos, trabalho, clubes; são as formações espontâneas. Já as intencionais são alimentadas por grupos ou mesmo por indivíduos que se articulam em prol de objetivos comuns. Neste último caso os participantes da rede podem atuar individualmente ou como atores sociais 6 .

Ao longo de mais de 70 anos de estudos das redes no mundo, muitas são as conceituações de rede e, vale a pena, neste momento, pontuar alguns deles, pois muitos são complementares. Como o próprio nome já denuncia, a rede é comparável com um tecido com múltiplos fios ligados entre si por nós, que se espalham por todos os lados, sem que nenhum deles seja central. Os integrantes de uma rede se ligam de forma horizontal a todos os outros. Nas redes todos têm o

\footnotetext{
${ }^{4}$ É um ponto de conexão, seja um ponto de redistribuição ou um terminal de comunicação.

${ }^{5}$ Deleuze e Guattari (1996) designam o rizoma como sendo um modelo que "liga um ponto qualquer a outro ponto qualquer (...) num sistema acêntrico, não hierárquico e não significante".

${ }^{6}$ Atores sociais representam ou atuam em nome de associações, movimentos, comunidades, empresas.
} 


\section{Periódica Eletrânica}

Fórum Ambiental

da Alta Paulista
Volume 11, Número 04, 2015

Educação Ambiental

mesmo poder de decisão, dependendo de uma vontade coletiva para realizar determinado objetivo (VIEZZER e OVALLES, 2002).

As redes têm sido um desafiador objeto de estudo de várias áreas do conhecimento humano. Fala-se em redes de celulares, de neurais artificiais, sociais, organizacionais, de sociedade-rede, de empresa-rede, de marketing-de-rede, de trabalho em rede, de rede de redes, entre outros. O termo rede define um conjunto de objetos (entidades, pessoas, organizações, grupos) interligado uns aos outros, permitindo circular elementos materiais ou imateriais, entre cada uma destas entidades, de acordo com regras definidas (MARTINHO, 2003).

As redes são sistemas organizacionais capazes de reunir indivíduos e instituições, de forma democrática e participativa em torno de causas e afins. $O$ conceito de redes transformou-se em uma alternativa prática de organizações, possibilitando processos capazes de responder às demandas de flexibilidade, conectividade e descentralização das esferas contemporâneas de atuação e articulação social. As redes possibilitam a articulação dos movimentos culturais e informacionais capazes de propor alternativas para a humanidade (OLIVIERI, 2008).

Castells (2003) diz que a rede representa um processo comunicacional simultâneo, no qual são compartilhadas informações, capital, cultura, e, que tem como arquétipo, a economia global.

Trabalhar em rede é bastante desafiador, tanto no âmbito pessoal quanto no profissional, pois exige um domínio nas técnicas de comunicação, o uso habilidoso e criativo das ferramentas tecnológicas, da revolução cultural, da internalização dos fundamentos e dos processos coletivos. A rede não cresce sozinha. O compartilhar é a estratégia do crescimento conjunto (AMARAL, 2008).

De acordo com Viera (2015), nos dias atuais as redes sociais são as mais comuns, reunindo mais de um bilhão de pessoas ao redor do mundo. Essa realidade do mundo digital influencia cada vez mais a comunicação, mudando a rotina de diversos profissionais, por causa da interatividade e rapidez. Hoje a comunicação pode ser feita de todos para todos.

$\mathrm{Na}$ perspectiva de Leite (2015), as redes sociais podem ser definidas como estruturas sociais virtuais constituídas por instituições, empresas ou indivíduos independentes de uma organização formal jurídica, conectadas por relações diversas, que comungam de competências, valores ou objetivos comuns. Estas vêm 
transformando a forma de comunicar das pessoas e das empresas, devido a sua capacidade de alcance mundial, influenciando opiniões e trazendo informações em questão de segundos. São exemplos de redes sociais, o Facebook, Youtube, o Twitter, o Instagram, sendo os dois primeiros os mais utilizados na atualidade, com cerca de 1,15 bilhões de usuários únicos e um bilhão de usuários, respectivamente.

As redes sociais influenciam no destino de diversas pessoas, deixando de lado tempo e espaço, pelas vias da rápida disponibilização de informações relevantes (MENDES, 2011). A comunicação nas redes ocorre de forma instantânea e tem alcance mundial, por isso se torna tão importante sua utilização como locus ideal para a mobilização dos indivíduos ou grupos em torno de objetivos comuns.

É nesse contexto que se enquadram as possibilidades vislumbradas para a educação ambiental, discutidas, principalmente, dentro das chamadas redes ambientais.

\subsection{REDES AMBIENTAIS}

De acordo com Ruscheinsky (2007), as redes ambientais, desde as locais até as globais, permitiram com que fosse intensificado o entendimento acerca da interrelação entre os problemas ambientais e as ações promovidas localmente. Tal promoção permite a articulação feita localmente e, aumenta em muito, a sua capacidade de influência das questões ambientais em nível global. Essa influência pode gerar até mesmo reversão em processos e/ou ações que afetariam as relações ambientais.

Ao longo dos anos foram criadas diversas redes no Brasil, que têm como objetivo fortalecer a educação ambiental, dentre as quais se destacam: a Rede Brasileira de Informação Ambiental (REBIA); a Rede Ambiental Escoteira (RAE); a Rede Brasileira de Educação Ambiental (REBEA); e na nossa região a Rede Paulista de Educação Ambiental (REPEA), entre outras que tem como objetivo integrar, articular e difundir as ações em educação ambiental.

Torna-se importante ainda compreender a educação ambiental para que se possa investigar mais profundamente os locus espaciais nos quais esta pode se desenvolver, sejam eles físicos ou virtuais. 


\subsection{EDUCAÇÃO AMBIENTAL}

Nos últimos séculos houve grandes mudanças no crescimento do conhecimento humano, alterando os valores e o modo de vida da sociedade. Fatores como o surgimento do processo industrial; o crescimento das cidades e o próprio sistema capitalista em si, estimulam cada vez mais o consumo em massa, aumentando a utilização dos recursos naturais e a produção de resíduos. Aos poucos, as consequências da modernidade foram aparecendo, principalmente, os problemas ambientais que alteram a qualidade de vida (ARAÚJO, 2015).

Em resposta a preocupação da sociedade com a qualidade de vida, surgiu a Educação Ambiental, que de acordo com a Política Nacional de Educação Ambiental - Lei no9795/1999, Art 1ำ, é definida como sendo:

(...) um processo de reconhecimento de valores e clarificações de conceitos, objetivando o desenvolvimento das habilidades e modificando as atitudes em relação ao meio, para entender e apreciar as inter-relações entre os seres humanos, suas culturas e seus meios biofísicos. A educação ambiental também está relacionada com a prática das tomadas de decisões e a ética que conduzem para a melhora da qualidade de vida (BRASIL, 1999).

Sua principal proposta é estimular o surgimento de uma cultura de interação entre natureza e sociedade, por meio da formação de uma atitude ecológica nas pessoas. A Educação Ambiental objetiva a formação de sujeitos capazes de compreender a sua realidade e agir de forma consciente (BRASIL, 1999).

A Educação Ambiental é umas das ferramentas utilizadas para sensibilizar e conscientizar a população sobre os problemas ambientais e tem como principais características ser um processo dinâmico; interativo; transformador; participativo; abrangente; globalizador; permanente; contextualizador e transversal (MARCATTO, 2002).

A família e a escola devem estar aliadas à Educação Ambiental, uma vez que são os iniciadores da educação para preservar o ambiente natural. Quanto mais cedo a criança for conscientizada do cuidado com o meio ambiente, maiores serão as chances dessa criança ser educada para o resto da vida.

Cada vez mais, a educação ambiental adota uma postura política, social e transformadora, que exige a responsabilidade e o comprometimento individual e 
coletivo de todos frente aos problemas ambientais (BRASIL, 2004). Além de envolver a própria vida, as questões ambientais, também envolvem a vida do planeta, colocando-se sobre ordem econômica e política, nacional e internacionalmente.

Considerada uma ferramenta motivadora e reflexiva, a educação ambiental busca harmonizar as relações entre o homem e o meio ambiente. "É por meio dessa busca que novas visões e mudanças são incorporadas na sociedade que ainda hoje vive emergida nos hábitos consumistas que alteram negativamente a qualidade ambiental" (OLIVEIRA e BARCELLOS, 2011, p. 7).

Para que a Educação Ambiental seja, de fato, incorporada enquanto prática é necessário fazer uso de instrumentos que facilitem a promoção dessa conscientização. Nessa direção, os meios de comunicação e, sobretudo, as redes, podem ser de grande auxílio para essa tarefa.

\subsection{A COMUNICAÇÃO NAS REDES}

Para analisar uma rede ou mesmo apenas entender o seu funcionamento, é fundamental entender o papel dos atores e processos que a sistematizam, assim como os tipos e fluxos de comunicação que se estabelecem nesse ambiente.

Nesse sentido, é importante que se possa entender a rede como um sistema e neste sistema a comunicação é responsável por estabelecer as relações entre os agentes que interagem neste ambiente. O conceito de sistema é bem anterior ao de rede, todavia, está intrinsecamente vinculado a este último. Para Sppeding (1975) entende-se sistema como o conjunto de componentes interativos designados por objetivos, limites e hierarquias, subsistemas e instituições que os integram e que são estruturados de acordo com o contexto externo.

De acordo com Bernardo e Bernardo (2013, p.46) pode-se afirmar que a comunicação é parte indissociável desse sistema. A comunicação “(...) entra em todos os momentos, em todos os processos, em cada parte e no todo, pois a comunicação é um princípio inato a um sistema e, portanto, aos subsistemas".

Diante de tal contexto, é importante que se compreenda como a informação, por meio da comunicação, vai fluir, passando entre os nós e os diversos graus de interação no convívio dos atores sociais que compõem estas redes. Como descreve 
Aguiar (2007), essas conexões têm sido representadas por meio de quatro metáforas.

A árvore é a primeira das metáforas e, representa o modelo no qual a informação é iniciada na raiz e, posteriormente, é difundida por meio dos ramos (denominados também de ramais). Estabelece um processo comunicacional que se expande até determinado ponto (caso seja cerceado) ou poderá ser incrementado ou desenrolado indeterminadamente, agregando novos integrantes. Tal concepção, como aponta Aguiar (2007), é um conceito antigo de rede de comunicação, no qual tiveram base os sistemas computacionais. Segue o princípio que pressupõe uma comunicação sob controle, hierarquicamente subordinada e, muitas vezes, em apenas uma direção, seguindo um fluxo unilateral.

Em seguida vem o conceito de malha, também denominada de trama. É a metáfora que traz a representação mais simples de rede, aquela integrada por ligações realizadas entre os nós de modo simétrico, exemplificado em uma rede de pesca, que molda as relações de comunicação em fluxos regulares de informação e nas quais as mensagens passam pelos nós por "contágio", como um vírus, um boato. "Por isso, sua dinâmica é imprevisível - tanto sobre como começou quanto como e quando vai parar" (AGUIAR, 2007, p.5).

Desenvolvida a partir de uma liderança ou de um facilitador, vem a metáfora da teia, que representa relações que se estabelecem radialmente. A função dessa coordenação é distribuir as mensagens recebidas de qualquer um dos nós para todos os demais nós que compõem a rede. Entretanto, embora pressuponha uma relação horizontal e não hierárquica, este modelo não permite a comunicação direta entre os integrantes da rede, toda e qualquer mensagem passa por um nó central (a liderança) que a distribui para os demais, de modo homogêneo (AGUIAR, 2007). Trata-se do modelo mais utilizado pelas redes organizacionais e interorganizacionais, e aí estão incluídas as ONGs e os movimentos sociais.

Por fim, apresenta-se a Rizoma que, segundo Aguiar (2007), é uma metáfora que busca atender os múltiplos processos assimétricos de comunicação que são desencadeados a partir de vários pontos ao mesmo tempo. Tal modelo prevê fluxos sem um centro estabelecido e não pressupõe uma regularidade de informações, tanto no tempo quanto no espaço. É caracterizada por fluxos que podem partir de qualquer ponto ou de vários simultaneamente e, ir para qualquer 
outro ponto dentro da rede. Desse modo, o papel de emissor e de receptor dentro do processo comunicacional passa a ser intercambiável e não há dependência de uma instância central para que a mensagem circule.

Caracteriza-se também pela heterogeneidade dos seus nós e vínculos: relações e sentidos são estabelecidos de modos muito diversos, e o rompimento de um ponto qualquer das cadeias de comunicação não compromete o reconhecimento do todo; rupturas, "linhas de fuga" $\mathrm{e}$ mecanismos de auto-reorganização são próprios da sua dinâmica (AGUIAR, 2007, p.6)

Portanto, pode-se dizer que a dinâmica de uma rede é correspondente ao modo como se estabelecem as relações no espaço e no tempo, sendo observados quatro aspectos, quais sejam: ritmo das relações e do fluxo de informação que se classifica em continuidade ou não, sazonalidade ou eventualidade, frequência e efeitos de participação dos integrantes da rede (AGUIAR, 2007).

Torna-se importante destacar que tanto o fluxo de informações quanto a horizontalidade que marcam as redes, não são suficientes para que a participação democrática plena seja garantida. Há a dependência da qualidade dos vínculos que são estabelecidos entre os integrantes da rede, assim como dos conteúdos mobilizadores.

\begin{abstract}
Qualquer pessoa pode contatar certos indivíduos e ignorar muitos outros (sobretudo quando a rede é muito extensa); ou comunicar-se mais intensamente com uns do que com outros; ou seja, pode manter vínculos fortes ou fracos, recíprocos e não-recíprocos. Vínculos fortes podem ser intensos e/ou duradouros; mas vínculos "fracos" (eventuais e/ou informais) não significam, necessariamente, comunicação menos eficaz ou menos relevante (AGUIAR, 2007, p.7).
\end{abstract}

Para esta pesquisa, torna-se relevante compreender as motivações e processos de aglutinação para a formação das redes, de modo a verificar quais são os fatores que possam favorecer uma maior integração entre os integrantes da rede. Apesar de toda rede já nascer de uma temática que motivou o interesse, como no caso - a educação ambiental, isso não basta para que todos os integrantes participem ativamente da rede. Para Aguiar (2007), os graus de participação que são estabelecidos dependem diretamente dos seguintes fatores: interesse na temática e nos conteúdos; fluxo das mensagens e o estímulo à participação; ações 
comunicativas; redução das barreiras à comunicação e da facilidade de domínio das tecnologias de comunicação e informação utilizadas.

\section{CONCLUSÃO}

Diante do contexto apresentado sob a estruturação das redes e o poder de mobilização, por meio da comunicação, nesse espaço virtual, as possibilidades que foram vislumbradas para a educação ambiental apresentam um potencial latente que pode ser concretizado devido a determinadas características promovidas pelas redes.

Dentre as principais características que levam à visualização de tal capacidade para o desenvolvimento da educação ambiental, pode-se destacar a rapidez com que as informações fluem nas redes, assim como o alcance de ordem global que esta pode atingir.

Ressalta-se também a capacidade de mobilização gerada pelas redes que, por meio das relações dialógicas estabelecidas, integra pessoas ou grupos em torno de objetivos comuns e estes são facilmente incorporados entre os integrantes das redes que ali já se encontram atraídos por "interesses" e preocupações semelhantes.

Torna-se importante destacar ainda que essa força mobilizadora, rápida e com alcance global, exercida no ambiente das redes, dependerá totalmente da qualidade dos vínculos de confiança estabelecidos entre os integrantes destas redes. Vínculos estes que podem ser fomentados por alguns elementos essenciais, quais sejam: interesse na discussão; estímulo à participação; redução das barreiras de comunicação, sobretudo, a do domínio das tecnologias. Ao transpor tais obstáculos, encontra-se o cenário ideal para que os integrantes participem ativamente das redes e sejam promotores de uma educação ambiental centrada na promoção de reflexão e articulação de saberes em prol da "saúde do planeta" e, consequentemente, no bem estar de todos.

\section{REFERÊNCIAS BIBLIOGRÁFICAS}


ABRANTES, R. F. Redes Ambientais. 2013. Disponível em:

$<$ http://pt.slideshare.net/rusgat/esquema-teorico-pratico-redes-ambientais> Acesso em: 29 de mar. 2015

AGUIAR, S. (2007). Redes sociais na internet: desafios à pesquisa. Anais do XXXI Congresso

Congresso Brasileiro de Ciências da Comunicação. Santos: Intercom - Sociedade Brasileira de Estudos Interdisciplinares da Comunicação.

AMARAL, V. Desafios do trabalho em rede. 2008. Disponível em: $<$ http://www.repea.org/index.php/conceitual/redes/84-desafios-do-trabalho-em-rede> Acesso em: 28 de mar. 2015

ARAÚJO, A. R. Afinal, o que é Educação Ambiental? 2015. Disponível em: <http://www.revistapontocom.org.br/artigos/afinal-o-que-e-educacao-ambiental> Acesso em: 22 de mar. 2015

BARBOSA, K. Por que as pessoas usam as redes sociais? 2011. Disponível em: <http://super.abril.com.br/blogs/tendencias/por-que-as-pessoas-usam-as-redes-sociais/> Acesso em: 28 de mar. 2015

BARNES, J.A. Social Networks. Cambridge: Module 26, p.1-29, 1972.

BERNARDO, Cristiane Hengler Corrêa ; BERNARDO, R.. Gestão da comunicação para o agronegócio. Cambiassu: Estudos em Comunicação (Online). v. 12, p. 43-55, ISSN: 21765111, 2013.

BRASIL, Ministério do Meio Ambiente. Os diferentes matizes da educação ambiental no Brasil: 1997-2007. Brasília (DF): MMA, 2008.

BRASIL. Ministério Público Federal. Política Nacional de Educação Ambiental. 1999. Disponível em: <http://pga.pgr.mpf.mp.br/boletins/arquivos-de-boletins-2009/politica-nacional-de-educacaoambiental/?searchterm=cfm> Acesso em: 22 de mar. 2015

BRASIL. Redes: uma introdução às dinâmicas da conectividade e da auto-organização. Brasília: WWF, 2004.

CASTELLS, Manuel. A sociedade em rede. In: A era da informação: economia, sociedade e cultura. Vol. 1. S. Paulo, Paz e Terra, 2003. $7^{\text {a }}$ ed. revista e atualizada.

DELEUZE, Gilles \& GUATTARI, Félix. O que é a Filosofia? Tradução de Bento Prado Jr. e Alberto Alonso Muñoz. Rio de Janeiro: Ed. 34, 1996.

LEITE, L.M. O que são redes sociais. 2015. Disponível em: < http://ogestor.eti.br/o-que-sao-redessociais/> Acesso em: 22 de mar. 2015

MARCATTO, C. Educação Ambiental: conceitos e princípios. Belo Horizonte: FEAM, 2002. 64p.

MARTINHO, C. Redes: Uma introdução às dinâmicas da conectividade e da auto-organização. Brasília: WWF, 2003. 91p.

MENDES, A. As redes sociais e sua influência na sociedade. 2011. Disponível em: <http://imasters.com.br/artigo/19889/redes-sociais/as-redes-sociais-e-sua-influencia-na-sociedade/> Acesso em: 28 de mar. 2015

OLIVEIRA, D. N; BARCELLOS, V. C. A. Rede de Educação Ambiental: Instrumentos para a capacitação de educadores ambientais. 2011. Disponível em:

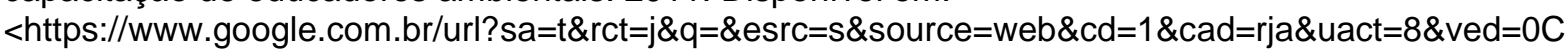
B0QFjAA\&url=https\%3A\%2F\%2Fnupeat.iesa.ufg.br\%2Fup\%2F52\%2Fo\%2F30_Artigo_EA_em_rede. doc\&ei=60QtVbrSOsa8ggSYloGgBQ\&usg=AFQjCNGUsZUe0YZqaQsAmefeXW' $s \_S I 7 \bar{h} 1$ w\&sig $\overline{2}=4 \mathrm{TV}$ LNod49H5IvD0bhC8ajQ> Acesso em: 08 de abril. 2015 
da Alta Paulista

OLIVEIRA, M. J. C; NADER, S. Comunicação Organizacional e Meio Ambiente: Uma análise sobre a relação entre políticas ambientais e de comunicação. 2007. Disponível em:

$<$ Http://www.abrapcorp.org.br/anais2007/trabalhos/gt2/gt2_oliveira.pdf> Acesso em: 22 de mar. 2015.

OLIVIERI, L. A importância histórico-social das Redes. 2008. Disponível em:

<http://www.repea.org/index.php/conceitual/redes/85-a-importancia-historico-social-das-redes> Acesso em: 28 de mar. 2015.

ROGERS, E. M.; KINCAID, D. L. Communication networks: toward a new paradigm for research. New York: Free Press, 1981.

RUSCHEINSKY, Aloísio. Atores socioambientais. Ministério do Meio Ambiente, p. 23, 2007.

SCOTT, J. Social Network analysis. Newbury Park, California: Sage Publications, 1992

SPPEDING, C.R.W. The biology of agricultural systems. London: Academic Press Inc., 1975.

VIEZZER, M. L; OVALLES, O. A Arte das Conexões. 2002. Disponível em:

$<$ http://www.repea.org/index.php/conceitual/redes/83-a-arte-das-conexoes> Acesso em: 20 de mar. 2015. 